\title{
Isolated Invasive Endomyocardial Cystic Echinococcosis Presenting with Heart Failure
}

\author{
Suleyman Ercan, ${ }^{1}$ Vuslat Bosnak, ${ }^{2}$ Murat Yuce, ${ }^{1}$ Vedat Davutoglu, ${ }^{1}$ and Fethi Yavuz ${ }^{1}$ \\ ${ }^{1}$ Department of Cardiology, School of Medicine, Gaziantep University, 27310 Gaziantep, Turkey \\ ${ }^{2}$ Department of Infectious Diseases, School of Medicine, Gaziantep University, 27310 Gaziantep, Turkey
}

Correspondence should be addressed to Murat Yuce, myuce@gantep.edu.tr

Received 30 March 2012; Accepted 19 June 2012

Academic Editor: T. A. Salerno

Copyright (C) 2012 Suleyman Ercan et al. This is an open access article distributed under the Creative Commons Attribution License, which permits unrestricted use, distribution, and reproduction in any medium, provided the original work is properly cited.

\begin{abstract}
Cardiac cystic echinococcosis is a rarely encountered parasitic infestation caused by Echinococcus granulasus larvae. Cystic echinococcosis hydatid composes $0.5-2 \%$ of all human cystic echinococcosis cases. Isolated cardiac involvement is very rare. Cardiac cystic echinococcosis hydatid generally accompanies another organ involvement, however, it might be isolated as in the present case and although rare and it can cause heart failure. We present a case of isolated apical cardiac cystic echinococcosis hydatid which leads to heart failure.
\end{abstract}

\section{Introduction}

Cardiac cystic echinococcosis is a rarely encountered parasitic infestation caused by Echinococcus granulasus larvae [1,2]. Cardiac cystic echinococcosis composes $0.5-2 \%$ of all human cystic echinococcosis cases. The most commonly involved organs are liver (55-70\%) and lung (18-35\%) [3]. Cardiac cystic echinococcosis usually accompanies other organ involvement. Isolated cardiac involvement is very rare. We present a case of isolated apical cardiac cystic echinococcosis which leads to heart failure.

\section{Case Presentation}

A 77-years-old female was referred to our clinic for evaluation of worsening heart failure. She had no history of international travel. During etiological evaluation of heart failure, echocardiography revealed an ejection fraction of $40 \%$ with a multilobular cystic structure localized to intramyocardial left ventricular apex (Figure 1). Computed tomography confirmed the diagnosis (Figure 2) and screening of other organ involvement including brain, lung, and liver were negative for cystic echinococcosis. Serum indirect hemagglutination assay test for Echinococcus granulasus was positive. Thus, diagnosis of isolated cardiac apical cystic echinococcosis was confirmed. The patient was recommended surgery, however, patient refused the surgical operation.

\section{Discussion}

Cystic echinococcosis is a parasitic infestation seen endemically in South America, South Europe, Africa, Turkey, Australia, New Zealand, and India due to E. granulosus $[1,2]$. Larvae of E. granulasus are excreted in feces of definite hosts like cat, dog, and wolf. Humans are infected by the food contaminated with these larvae and become intermediate hosts [3].

Cyst hydatid mostly involves liver (55-70\%) and lung $(17-35 \%)$, however, cardiac involvement is rare $(0.5-2 \%)$. Cardiac involvement are usually accompanied by other organ involvement $[4,5]$. Cardiac cystic echinococcosis involves most commonly left ventricle $(75-55 \%)$, right ventricle (15-18\%), interventricular septum (5-9\%), right atrium (3-4\%), and interatrial septum (2\%). Less commonly it involves pericardium and pulmonary artery. Cardiac cystic echinococcosis most commonly involves left ventricular wall possibly due to increased coronary blood flow [6].

Cardiac cystic echinococcosis is usually asymptomatic. Symptoms vary according to localization and dimensions of the cyst. Patients usually present with three main symtoms: 


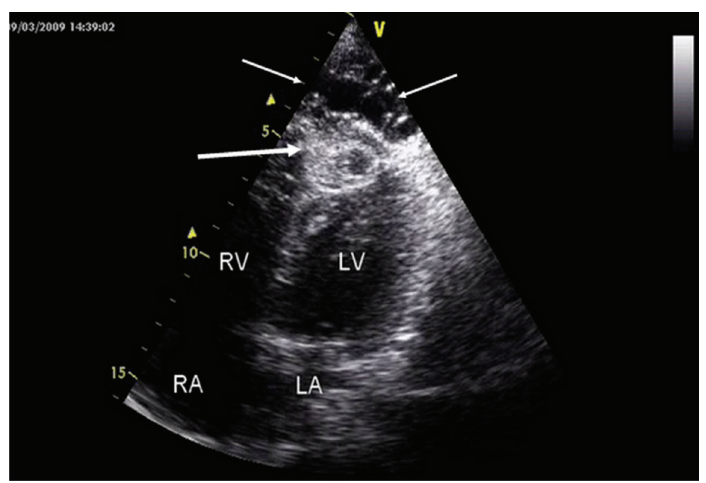

Figure 1: Apical four chamber view, revealing multiple hydatid cysts. Multiple small cysts surrounding and obliterating the apical region (small arrows). Relatively bigger cyst invasing the apicoseptal region (big arrow).

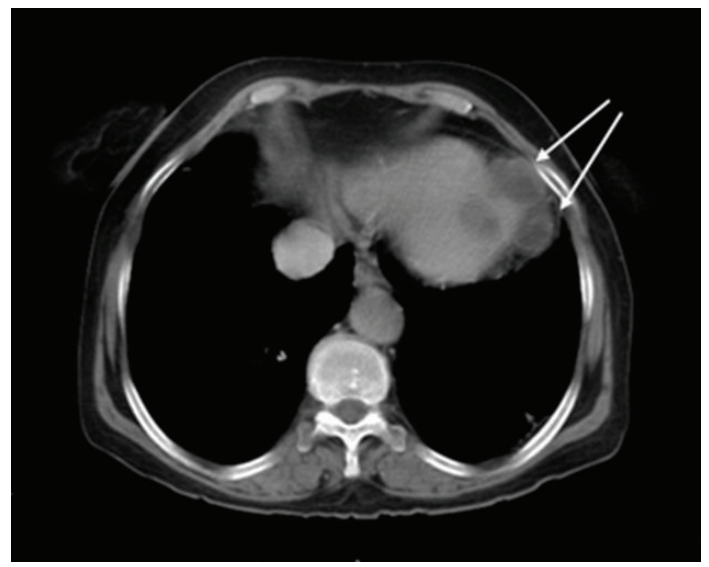

FIgURE 2: Computed tomography revealing multiple cystic echinococcosis. Multiple cysts surrounding apical region (arrows).

dyspnea, chest pain, and palpitations. Other rare symptoms include fever, cough, hemoptysis, syncope, and sudden death. Our patient was suffering from dyspnea due to pulmonary edema.

Although cystic echinococcosis grows usually very slowly in the myocardium and may remain asymptomatic for a long period it can also show rapid progression [7]. Early diagnosis of cardiac cystic echinococcosis is rather difficult beacuse of long interval between beginning of the infestation and development of symptoms and besides symptoms are nonspecific [8].

Diagnosis of cardiac cystic echinococcosis is easier in the presence of other organ involvement like liver and lung, but it is difficult in isolated cardiac involvement. Although CT and MRI give detailed information about the cyst and its localization, echocardiography is the best noninvasive method for diagnosis of cardiac cystic echinococcosis [9].

Although the course of cardiac cystic echinococcosis is usually asymptomatic, it may cause life-threatening complications including sudden death, anaphylactic shock, peripheral pulmonary emboli and cerebral emboli, acute coronary syndrome, heart failure, and arrhythmia. Therefore, cardiac cystic echinococcosis should be treated by surgical intervention even they are asymptomatic.

In conclusion, cardiac cystic echinococcosis is generally accompanies other organ involvement, however, it might be isolated as in the present case and although rare, and it can cause heart failure.

\section{References}

[1] S. A. Abu-Eshy, "Some rare presentations of hydatid cyst (Echinococcus granulosus)," Journal of the Royal College of Surgeons of Edinburgh, vol. 43, no. 5, pp. 347-352, 1998.

[2] R. A. Brown, A. J. W. Millar, Z. Steiner, J. E. J. Krige, D. Burkimsher, and S. Cywes, "Hydatid cyst of the pancreas-a case report in a child," European Journal of Pediatric Surgery, vol. 5, no. 2, pp. 121-124, 1995.

[3] WHO/OIE, "Echinococcosis in humans: clinical aspects, diagnosis and treatment," in Manual on Echinococcosis in Humans and Animals: A Public Health Problem of Global Concern, J. Eckert, M. A. Gemmell, F. X. Meslin, and Z. S. Pawlowski, Eds., pp. 20-66, World Organisation for Animal Health, Paris, France, 2001.

[4] A. Kir and E. Baran, "Simultaneous operation for hydatid cyst of right lung and liver," Thoracic and Cardiovascular Surgeon, vol. 43, no. 1, pp. 62-64, 1995.

[5] M. Guntz, B. Coppo, G. Lorimier, and P. Cronier, "The hydatid cysts of the liver lately revealed ( 10 to 22 years) after the surgical treatment of a pulmonary hydatidosis," Journal de Chirurgie, vol. 127 , no. 8-9, pp. 375-381, 1990.

[6] I. Tengiz, "Cardiac hydatic cyst," Journal of Cardiac Research, vol. 1, pp. 1-5, 2006.

[7] S. Soydinc, V. Davutoglu, and M. Oylumlu, "Progress of untreated massive cardiac echinococcosis-echocardiographic follow-up," Echocardiography, vol. 23, no. 9, pp. 780-783, 2006.

[8] R. Rivera and J. L. Delcan, "Surgical treatment of coronary insufficiency produced by cardiac echinococcosis," Chest, vol. 78, no. 6, pp. 849-852, 1980.

[9] O. K. Salih, S. K. Celik, M. S. Topcuoglu, B. Kisacikoglu, and A. Tokcan, "Surgical treatment of hydatid cysts of the heart: a report of 3 cases and a review of the literature," Canadian Journal of Surgery, vol. 41, no. 4, pp. 321-327, 1998. 


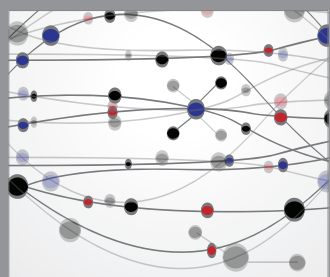

The Scientific World Journal
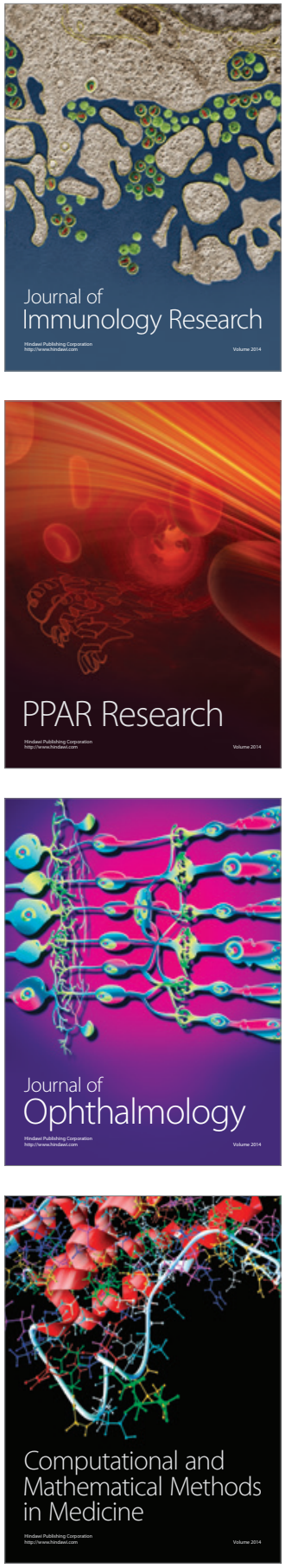

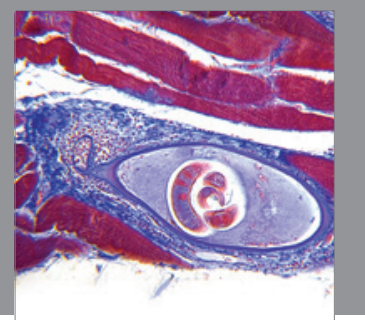

Gastroenterology

Research and Practice
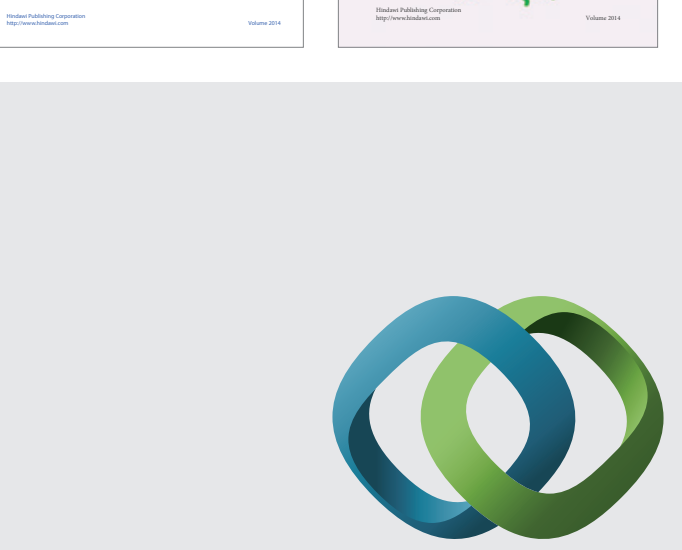

\section{Hindawi}

Submit your manuscripts at

http://www.hindawi.com
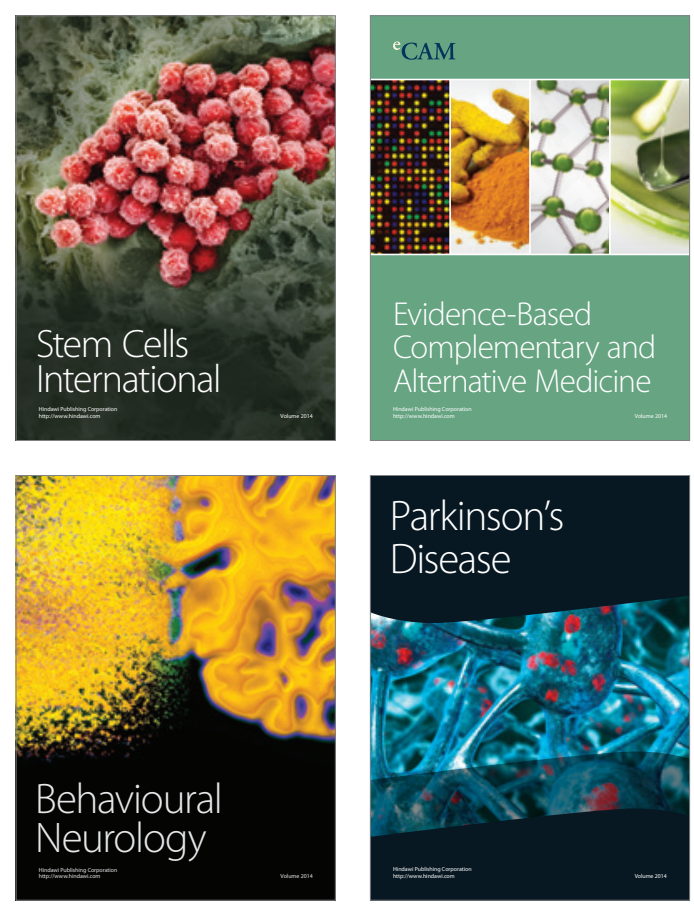

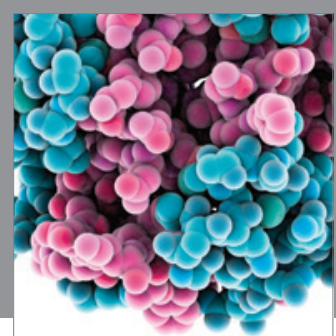

Journal of
Diabetes Research

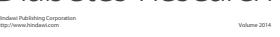

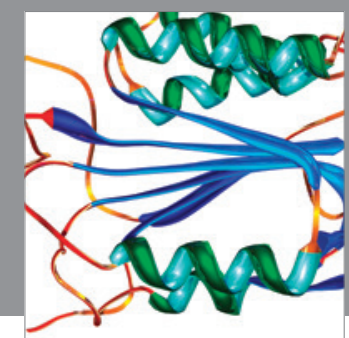

Disease Markers
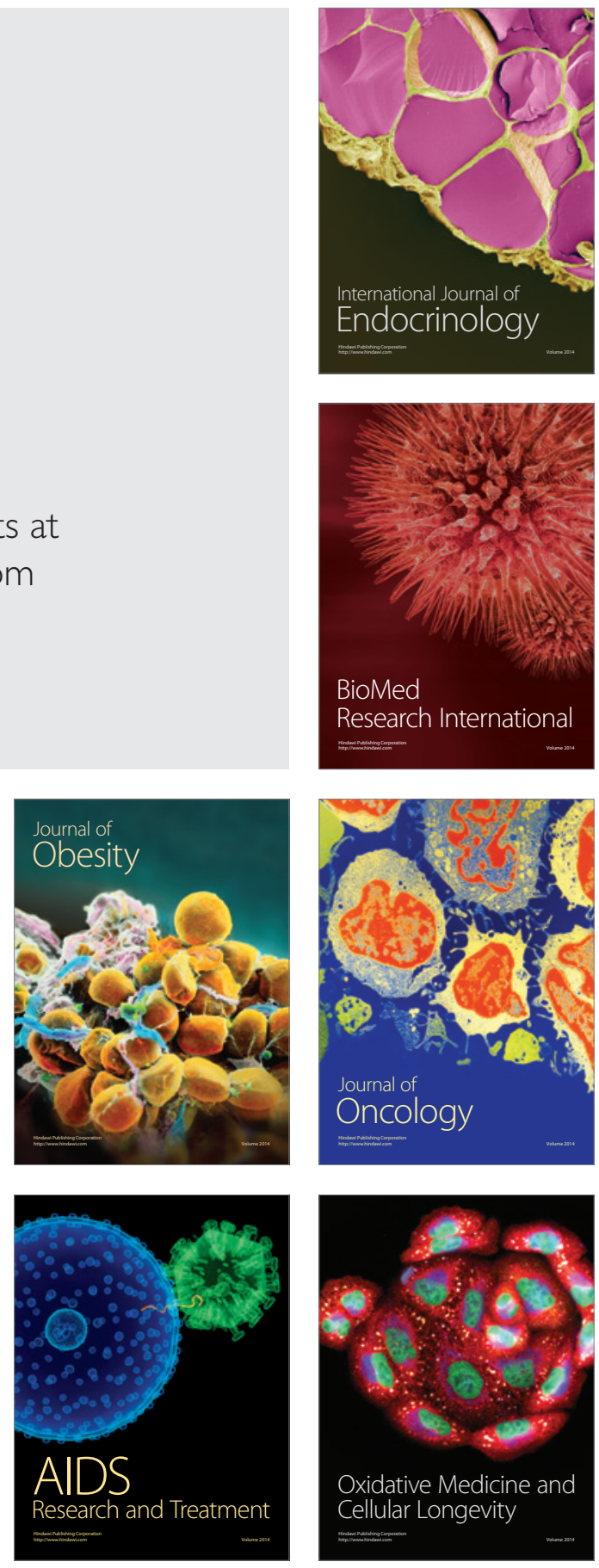